\title{
Intramolecular Mobility in Nitroxide Biradicals with Flexible Linkers
}

\author{
Günter Grampp ${ }^{1}$ • Van Anh Tran ${ }^{2}$ Petr V. Pantyukhov ${ }^{3}$ - Alexander I. Kokorin ${ }^{3,4}$
}

Received: 24 May 2020 / Revised: 10 July 2020 / Published online: 29 September 2020

(c) The Author(s) 2020

\begin{abstract}
Intramolecular electron spin exchange has been studied by X-band electron paramagnetic resonance (EPR) spectroscopy in two long-chain flexible nitroxide biradicals existing in fluid solutions in three spectroscopy-different spatial conformations as a function of temperature, solvent viscosity and polarity. Certain thermodynamic parameters of the conformational transitions were calculated from the EPR spectra. The process of spin-exchange in these biradicals dissolved in five different alcohols was compared with that in the non-polar solvents (toluene) and aprotic (acetonitrile), as well as with two other biradicals studied earlier, and with thermodynamic characteristics of the solvents. A distinct correlation was found between macroscopic (solvent viscosity) characteristics of solvents and thermodynamic parameters of the intramolecular conformational transitions.
\end{abstract}

\section{Introduction}

Professor Lebedev has paid special attention to various paramagnetic systems revealed inter-spin interactions among which electron spin exchange was of particular interest. Stable nitroxide biradicals represent a large class of such compounds that can be formally divided by several groups, e.g., chemically rigid, short-chain flexible, long-chain flexible, etc. A lot of articles describing electron spin exchange phenomena observed by EPR (electron paramagnetic resonance) spectroscopy were published during the last 50 years [1-15] and in references therein. Despite such huge number of publications which have analyzed the effect of chemical nature, the length of the spacer,

Günter Grampp

grampp@tugraz.at

1 Institute of Physical and Theoretical Chemistry, Graz University of Technology, Graz, Austria

2 School of Chemical Engineering, Hanoi University of Science and Technology, Hanoi, Vietnam

3 Plekhanov Russian University of Economics, Moscow, Russian Federation

4 N. N. Semenov Federal Research Center for Chemical Physics, Russian Academy of Sciences, Moscow, Russian Federation 
temperature, solvent polarity, and viscosity, etc., the papers regarding this item are still appeared in the literature (see, e.g., [16-20] in which influence of high pressure [17], specific solvation in room temperature ionic liquids [19] or the structure of the nitroxide radicals [20] on the dynamics of the intramolecular motions were examined. We should note that the interest in flexible long-chain biradicals continues being actual due to the importance of any new information concerning them.

Biradicals are in general more or less flexible, even those which look like chemically rigid systems [21-24], exist in liquid low-viscose solutions in several conformations with transitions among them [4-8, 11]. Long-chain flexible nitroxide biradicals contain usually at least ten intermediate chemical bonds between nitroxide rings, which can contain $-\mathrm{S}-,-\mathrm{NH}-,-\mathrm{CH}_{2}-,-\mathrm{OCH} 2 \mathrm{CH} 2-,-\mathrm{CONH}-,-\mathrm{COO}-$, etc., atoms and groups.

It was shown in $[4,11]$ that the EPR spectroscopic behaviour of the long-chain biradicals in liquid solutions with low viscosities can be described in terms of the threeconformational model with transitions among them which was represented in detail in Refs. [4, 5, 18, 20]. Such spin labelled "oligomers" were described in terms of short polymeric systems with a reasonable agreement with theory [6]. Peculiarities of such EPR spectra and their features are discussed below reflecting transitions between all conformations. The correctness of the model suggested in [4] was confirmed in all publications cited above.

In a previous paper, the effect of solvating paramagnetic $>\mathrm{N}-\mathrm{O}$ fragments in various media in the case of two biradicals with different functional groups in the bridge connecting two nitroxide rings, $\mathrm{S}\left[\left(\mathrm{CH}_{2}\right)_{4} \mathrm{COOR}_{6}\right]_{2}(\mathbf{B 3})$ and $\left(\mathrm{CH}_{2}\right)_{5}\left[\mathrm{CONHR}_{6}\right]_{2}(\mathbf{B 4})$, where $\mathrm{R}_{6}$ is 1-oxyl-2,2,6,6-tetramethylpiperidine ring, has been reported [11]. That was the first attempt to analyse systematically the influence of the solvent nature on conformational transitions in long-chain flexible biradicals. This effect on intramolecular spin exchange in biradical systems is still one of the most unclear issues in the physical chemistry of nitroxide biradicals. Indeed, the authors of Ref [11]. tried to find correlations between dynamic and thermodynamic parameters calculated from EPR spectra recorded at different temperatures (see below) and such solvent characteristics as vis$\operatorname{cosity} \eta$, a characteristic activation energy value $E_{\eta}$ which has revealed a non-linear dependence, with the widely used parameters like the so-called 'Dimroth and Reichardt's' $E_{\mathrm{T}}$ (30) [25] and Kamlet and Taft's $\pi^{*}$ [26], the longitudinal relaxation time, $\tau_{\mathrm{L}}$, which is known to play an important role in intermolecular electron transfer [27]. Unfortunately, no one parameter could perform reasonably good quantitative correlation with experimental data performed in Ref. [11].

In this paper, we describe the effect of solvents with different viscosities and polarities on the intramolecular electron spin exchange in two other flexible longchain nitroxide biradicals.

\section{Experimental}

Biradicals $\left(\mathrm{CH}_{2}\right)_{8}\left[\mathrm{COOCH}_{2} \mathrm{CH}_{2} \mathrm{R}_{6}\right]_{2}(\mathrm{~B} 1)$ and $\left(\mathrm{CH}_{2}\right)_{8}\left[\mathrm{CONHR}_{6}\right]_{2}(\mathrm{~B} 2)$ in which $\mathrm{R}_{6}$ is 1-oxyl-2,2,6,6-tetramethylpiperidine residue, used in this work, were synthesized as described in $[2,3,28]$ and their colors and melting points were in good correlation with the published ones. 
Toluene, acetonitrile, methanol, ethanol, 1-butanol, 1-octanol, and cyclohexanol were selected as solvents because of their different viscosities and polarities. All organic solvents were specially purified according to literature procedures [29]. Solutions were prepared, bubbled with nitrogen for 20-25 min, where after $0.5 \mathrm{~mL}$ was taken to a thin capillary under nitrogen, degassed by freeze-pumpthaw cycles to remove molecular oxygen, and finally sealed off under vacuum. In the cases of 1-octanol and cyclohexanol, solutions were heated slightly while bubbling. Radical concentrations were kept sufficiently low $\left(\leq 5 \times 10^{-4} \mathrm{M}\right)$ to eliminate intermolecular exchange broadening [30].

EPR spectra were recorded with a Varian E-101 X-band spectrometer equipped with a JEOL JNM-VT-30 temperature control unit (accuracy $\pm 1 \mathrm{~K}$ ) within a temperatures range of 263-393 K. The following parameters: the hyperfine splitting (hfs) constant $a$, the amplitudes and line widths of lines 1 and 2 (Fig. 1) were experimentally measured.

For flexible rather long-chain molecules, the influence of the solvent can be discussed as the "cage effect" [4, 5]. Temperature changes of the quintet spectra shown in Fig. 1 are typical for the case of strong $(|J|>>a)$ exchange between three conformations: an "elongated" conformer ' 1 ' with $J_{1}=0$ and lifetime $\tau$, and two conformations ' 2 ' and ' 3 ' with total lifetime ' $\tau_{\mathrm{C}}$, in which the radical fragments are located nearby each other in the "cage" of the solvent molecules but with $J_{2}=0$, and $\left|J_{3}\right|>>a[4,5]$. The movement of the radical fragments inside the cage is fast, and transitions from outside to inside the cage are slow, i.e., $a \cdot \max$ $\left(\tau, \tau_{\mathrm{C}}\right)>1[4,5]$. Some thermodynamic parameters of the intramolecular transitions in the long-chain biradicals can be calculated. The ratio $\tau_{\mathrm{C}} / \tau$ can be estimated from the experimental EPR spectra by the ratio of the integral intensities $I_{2}$ and $I_{1}$ of the lines $2,2^{\prime}$ and $1,1^{\prime}$ respectively, according to [4]:

Fig. 1 EPR spectra of biradical B1 in acetonitrile at 263 (a), 283 (b), 313 (c), and $343 \mathrm{~K}$

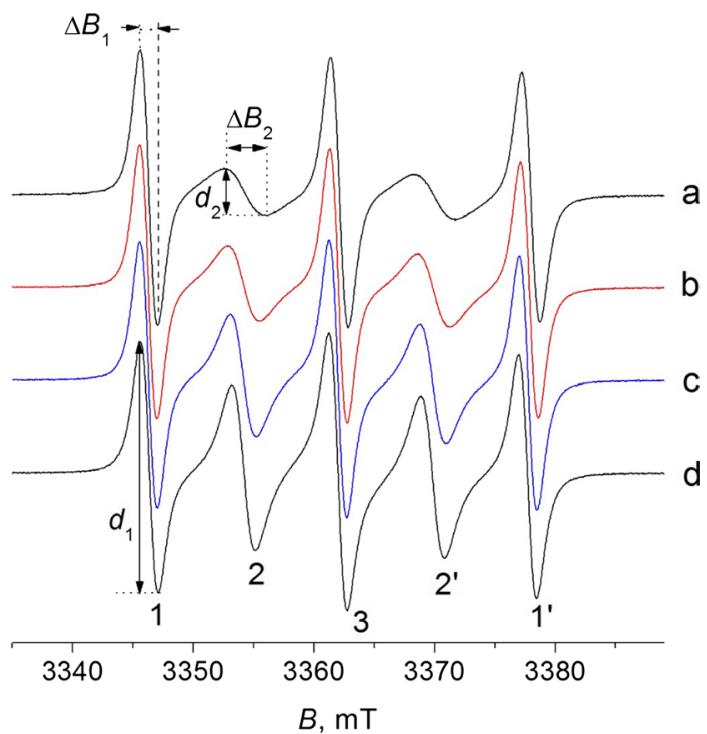




$$
I_{2} / I_{1} \approx d_{2}\left(\Delta B_{2}\right)^{2} / d_{1}\left(\Delta B_{1}\right)^{2},
$$

where $d_{1}$ and $d_{2}$ are the amplitudes and $\Delta B_{1}$ and $\Delta B_{2}$ the widths of lines 1 and 2 averaged over the lines 1 and $1^{\prime}$ or 2 and $2^{\prime}$ (see Fig. 1). It has been obtained that [4]:

$$
\tau_{\mathrm{C}} / \tau=3\left(I_{2} / I_{1}\right) /\left[2-\left(I_{2} / I_{1}\right)\right] .
$$

The analysis of lines 2 and $2^{\prime}$ narrowing with temperature led to conclude that the motion of the radical fragments inside the cage. In the case of fast modulation of the exchange interaction, the exchange broadening $1 / T_{2}$ of these lines is described by the expression $[4,5]$ :

$$
\frac{1}{T_{2}}=\frac{a^{2} \tau_{\text {eff }}}{4},
$$

where $\tau_{\text {eff }}$ is a complex combination of the modulation parameters and its value is close to the longest characteristic times of the intramolecular motions. For Lorentzian lines, $a$ is taken in frequency units, and $\gamma_{\mathrm{e}}$ is the gyromagnetic ratio of the free electron.[4]:

$$
a \tau_{\text {eff }}=2 \sqrt{3}\left|\gamma_{e}\right|\left(\Delta B_{2}-\Delta B_{1}\right) / a
$$

Supposing the Arrhenius dependence between $\tau_{\mathrm{C}} / \tau, \tau_{\text {eff }}$ and the temperature $T$ is

$$
\begin{gathered}
\tau_{\mathrm{C}} / \tau=\exp (\Delta S / R-\Delta H / R T), \\
\tau_{\text {eff }}=\tau_{0} \exp \left(\frac{\varepsilon}{\mathrm{RT}}\right)
\end{gathered}
$$

one can calculate the values of the enthalpy $\Delta H$ and the entropy $\Delta S$ of the cage, as well as the parameters $\varepsilon$ and $\tau_{0}$, which characterize movements inside the cage. Here $\tau_{0}$ is the characteristic time of the motions by which a transition between the conformation with $J_{2}=0$ and $\left|J_{3}\right|>>a$, would take place at the absence of the activation energy barrier $\varepsilon$ between them.

\section{Results and Discussion}

Typical electron paramagnetic resonance (EPR) spectra of biradical B1 in acetonitrile at different temperatures are given in Fig. 1. For biradical B2, similar spectra have been recorded. For both biradicals, the temperature behavior of the spectra is analogous in all the solvents, but an interval of these changes sufficiently depended on its nature. Similar changes have been observed also for biradicals B3 and B4 in [11].

As an example, temperature dependences of the hfs constant $a$ and the ratio $\tau_{\mathrm{c}} / \tau$ (in the Arrhenius plots) for biradicals B1 and B2 dissolved in methanol, ethanol, and toluene are given in Fig. 2. Temperature dependences of $a$ are usually characterized 
Fig. 2 Temperature dependences of $(A)$ the hfs constant $a$ and $(B) \ln \left(\tau_{\mathrm{C}} / \tau\right)$ for biradical $\mathbf{B} \mathbf{1}$ (filled circle, open circle) and B2 (filled triangle) dissolved in methanol (filled circle), ethanol (open circle), and toluene (filled triangle)
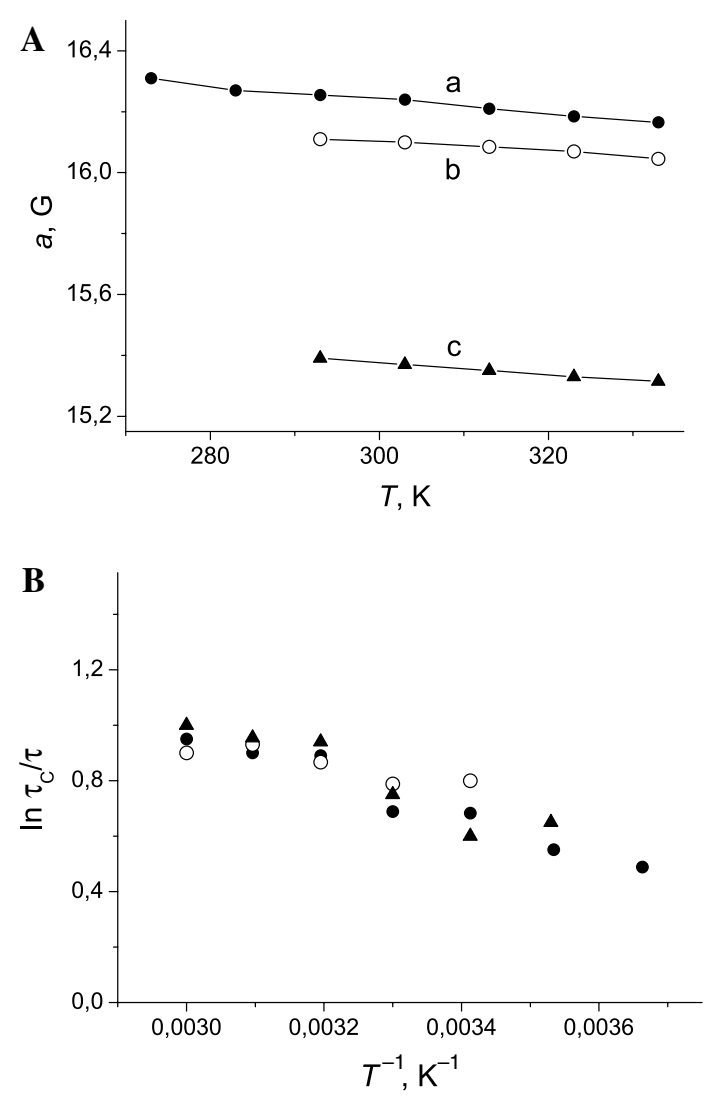

Table 1 Thermodynamic parameters $\Delta H$ and $\Delta S$ of radicals $\mathrm{B} 7$ and $\mathrm{B} 12$

\begin{tabular}{lllllll}
\hline Solvent & $\mathrm{d} a / \mathrm{d} T, \mathrm{G} / \mathrm{K}$ & & \multicolumn{2}{l}{ Biradical B1 } & & \multicolumn{2}{l}{ Biradical B2 } \\
\cline { 6 - 7 } \cline { 5 - 6 } & & $\Delta H, \mathrm{~kJ} / \mathrm{mol}$ & $\Delta S, \mathrm{~J} / \mathrm{mol} \mathrm{K}$ & & $\Delta H, \mathrm{~kJ} / \mathrm{mol}$ & $\Delta S, \mathrm{~J} / \mathrm{mol} \mathrm{K}$ \\
\hline Methanol & -0.0024 & $5.7 \pm 1$ & $30 \pm 6$ & & $7.2 \pm 1$ & $20 \pm 2$ \\
Ethanol & -0.0017 & $2.4 \pm 0.5$ & $8.1 \pm 10$ & & $4.0 \pm 0.6$ & $26 \pm 3$ \\
Acetonitrile & -0.0021 & $3.2 \pm 1$ & $1.9 \pm 1$ & & $0.31 \pm 0.3$ & $9.2 \pm 2$ \\
Toluene & -0.0019 & - & - & $4.7 \pm 1$ & $19 \pm 8$ \\
\hline
\end{tabular}

by the parameter $\mathrm{d} a / \mathrm{d} T$ [31] calculated from the EPR spectra, which are listed in Table 1 . These values are very close to those presented in [11,31] for biradicals and radicals with the same $\mathrm{R}_{6}$ ring in their structure reflecting changes of a upon temperature variation.

Earlier, for biradicals $\mathbf{B 3}$ and $\mathbf{B 4}$ [11], it has been shown that in protic solvents $\tau_{\mathrm{c}} / \tau$ decreases slightly with temperature, while in an aprotic solvent (toluene) $\tau_{\mathrm{c}} / \tau$ increases. Temperature changes of these parameters were very small since, for the long-chain biradicals, entrance into the cage is mainly connected with the 
Fig. $3 a \tau_{\text {eff }}$ as a function of temperature for biradical B1 dissolved in methanol (filled circle), ethanol (open circle), 1-butanol $(\nabla)$, 1-octanol (filled triangle), cyclohexanol $(\Delta)$, toluene $(X)$, acetonitrile (upside down filled triangle)

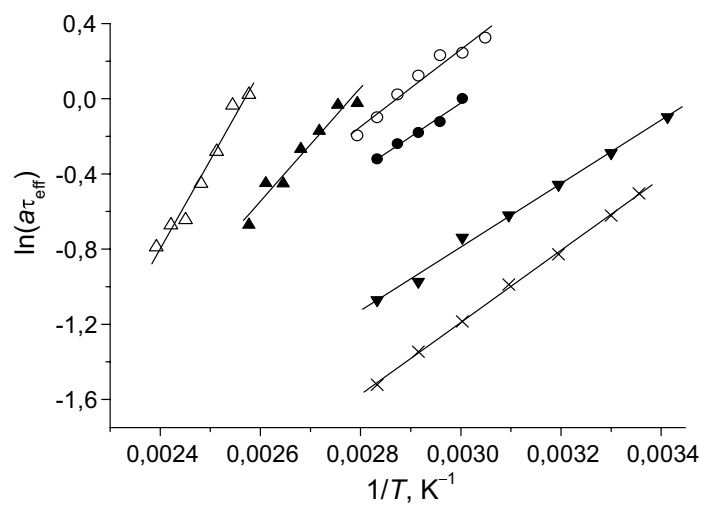

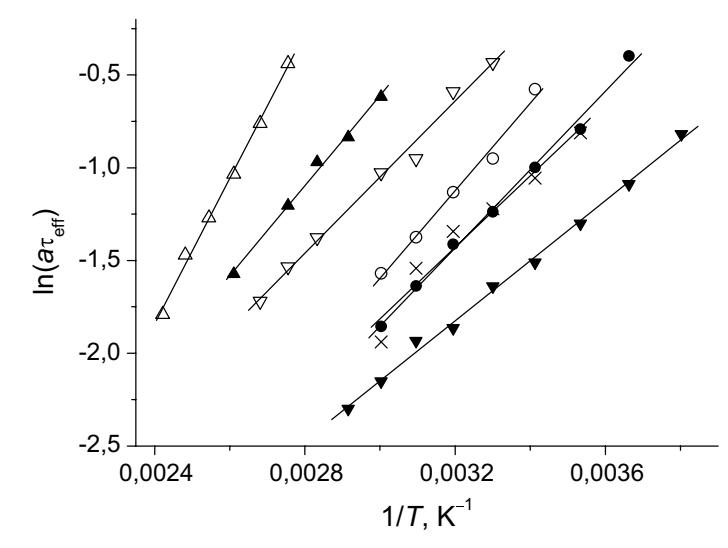

Fig. $4 a \tau_{\text {eff }}$ as a function of temperature for biradical B2 dissolved in methanol (filled circle), ethanol (open circle),1octanol (filled triangle),

cyclohexanol $(\Delta)$, toluene $(X)$, acetonitrile (upside down filled triangle)

steric, i.e. entropic, and not energetic factors [11]. Estimated parameters $\Delta H$ and $\Delta S$ in toluene were equal to $3.6 \mathrm{~kJ} \mathrm{~mol}^{-1}$ and $16.7 \mathrm{~J} \mathrm{~mol}^{-1} \mathrm{~K}^{-1}$, which is in good agreement with those published in [4]. In our case, parameters given in Table 1 (see also Fig. $2 \mathrm{~b}$ ) represent a fact that $\Delta H$ has positive values, i.e., $\tau_{\mathrm{c}} / \tau$ increases slightly with temperature for all types of the solvent. To clarify this fact, it will be necessary to investigate this in more detail later. Surprisingly, we could not find a straight correlation between $\tau_{\mathrm{c}} / \tau, \Delta H$ and $\Delta S$ parameters and the viscosity of the solvents used.

Figures 3 and 4 show linear dependences on the temperature of $a \tau_{\text {eff }}$ values in all solvents used for both $\mathbf{B 1}$ and $\mathbf{B 2}$ biradicals as it has been also observed in the case of $\mathbf{B 3}$ and $\mathbf{B} 4$ [11]. The appropriate thermodynamic parameters $\varepsilon$ and $\tau_{0}$ were calculated for biradicals $\mathbf{B} 1$ and $\mathbf{B} 2$ by Eq. (6) and are listed in Table 2. In both cases, noticeable differences in the temperature - $a \tau_{\text {eff }}$ behavior, depending on the alcohol molecule size, were observed and they are comparable with those calculated for $\mathbf{B 3}$ and $\mathbf{B 4}$ in [11]. Note that a plot for $\mathbf{B 4}$ in water is in the same order [11]. $\varepsilon$ values increase systematically, twofold from methanol to cyclohexanol (Table 2). The solvent characteristics such as viscosity at $298 \mathrm{~K}, \eta$, 
Table 2 Thermodynamic parameters $\varepsilon$ and $\tau_{0}$ for biradicals $\mathbf{B 1}$ and $\mathbf{B 2}$

\begin{tabular}{llllll}
\hline Solvent & \multicolumn{2}{l}{ Biradical B1 } & & \multicolumn{2}{l}{ Biradical B2 } \\
\cline { 2 - 3 } \cline { 5 - 6 } \cline { 5 - 6 } & $\varepsilon, \mathrm{kJ}^{2} \mathrm{~mol}^{\mathrm{a}}$ & $-\log \tau_{0}^{\mathrm{b}}$ & & $\varepsilon, \mathrm{kJ} / \mathrm{mol}^{\mathrm{a}}$ & $-\log \tau_{0}{ }^{\mathrm{b}}$ \\
\hline Methanol & 16.50 .4 & 12.0 & & 14.90 .3 & 10.8 \\
Ethanol & 19.60 .5 & 12.2 & & 17.10 .4 & 11.0 \\
1-Butanol & 17.20 .4 & 11.6 & & 21.30 .4 & 10.0 \\
1-Octanol & 20.10 .5 & 11.9 & & 25.10 .5 & 12.1 \\
Cyclohexanol & 32.50 .8 & 13.4 & 39.30 .7 & 13.8 \\
Toluene & 16.00 .4 & 11.8 & & 15.90 .3 & 11.5 \\
Acetonitrile & 13.50 .3 & 11.5 & & 14.00 .3 & 11.0 \\
\hline
\end{tabular}

${ }^{\mathrm{a}}$ Error is $10 \%$

${ }^{\mathrm{b}}$ Error is 0.3

the viscosity energy, $E_{\eta}$, the solvent dielectric constant, $\varepsilon_{\mathrm{S}}$, are given in Table 3 for easier comparison with the data listed in Table 2. Two solvents (toluene, acetonitrile) did not reveal such regularity. Parameters $\tau_{0}$ for both biradicals do not practically depend on the solvent nature. Their values around $\sim 10^{-11}-10^{-12} \mathrm{~s}$ are characteristic for rotational movements around usual $\sigma$-bonds.

A correlation between $\varepsilon$ and solvent viscosity $\eta$ has already been reported for short-chain flexible nitroxide biradicals [38], taking a linear dependence of $\ln \eta$ vs. $\mathrm{T}^{-1}$ with a characteristic activation energy value $E_{\eta}$. It was interesting to compare the behavior of a bulk macroscopic characteristic of the solvent $(\eta)$ with a similar parameter on the microscopic level ( $\tau_{\text {eff }}$ or experimentally measured $a \tau_{\text {eff }}$ ). Viscosity parameters $\eta$ for all solvents were taken from [32, 33]. Indeed, we have observed the appropriate experimental dependencies in all protic and other solvents used both for B1 and B2 (Fig. 5). Note that the correlation between $\varepsilon$ and $E_{\eta}$ revealed also a similar dependence for biradicals B3 and B4 (the corresponding values in Fig. 5 are taken from [11]. It follows from our data that the molecular motions (i.e., conformational rearrangements) inside the cage depend on the bulk characteristics of the cage, which is formed by the corresponding solvent molecules.

Table 3 Physical properties of the solvents used

\begin{tabular}{llll}
\hline Solvent & $\eta, \mathrm{cP}$, at $298 \mathrm{~K}^{\mathrm{a}}$ & $E_{\eta}, \mathrm{kJ} / \mathrm{mol}^{\mathrm{b}}$ & $\varepsilon_{\mathrm{S}}$ \\
\hline Methanol & 0.551 & 11.3 & $32.5^{\mathrm{c}}$ \\
Ethanol & 1.08 & 15.0 & $24.3^{\mathrm{c}}$ \\
1-Butanol & 2.57 & 19.8 & $16.0^{\mathrm{d}}$ \\
1-Octanol & 7.36 & 24.9 & 10.3 \\
Cyclohexanol & 41.3 & 41.7 & $15,0^{\mathrm{e}}$ \\
Acetonitrile & 0.369 & 7.5 & $35.8^{\mathrm{f}}$ \\
Toluene & 0.553 & 9.1 & 2.4 \\
\hline
\end{tabular}

The data were mainly taken from [17] unless otherwise noticed ${ }^{\mathrm{a}}$ From [32, 33], ${ }^{\mathrm{b}}$ [32], ${ }^{\mathrm{c}}$ [34], ${ }^{\mathrm{d}}$ [35], ${ }^{\mathrm{e}}$ [36], ${ }^{\mathrm{f}}$ [37] 
Fig. $5 \varepsilon$ as a function of $E_{\eta}$ for biradicals B1 (filled circle), B2 (open circle), $\mathbf{B 3}$ (filled triangle), and $\mathbf{B} \mathbf{4}(\Delta)$ in different solvents

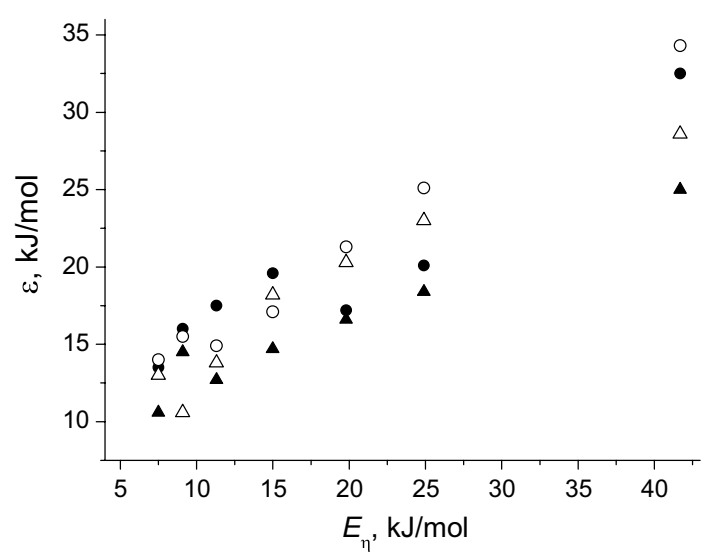

The results obtained allowed us to compare values of $\varepsilon$, characterizing movements of the nitroxide rings inside the cage of solvent molecules, with parameters characterizing properties of the solvent, first of all of viscosity $\eta$, or better to say with the characteristic activation energy value $E_{\eta}$. The results obtained for all B1-B4 biradicals are shown in Fig. 5. One can conclude that there is a rather evident practically linear correlation between $\varepsilon$ and $E_{\eta}$ in total. The differences, which could be observed between all four biradicals B1-B4 in Fig. 5 are likely to be attributed to the differences in the bridges of the biradicals as their nitroxide fragments are identical.

\section{Conclusions}

Two nitroxide biradicals $\left(\mathrm{CH}_{2}\right)_{8}\left[\mathrm{COOCH}_{2} \mathrm{CH}_{2} \mathrm{R}_{6}\right]_{2}$ (B1) and $\left(\mathrm{CH}_{2}\right)_{8}\left[\mathrm{CONHR}_{6}\right]_{2}$ (B2), where $\mathrm{R}_{6}$ is 1-oxyl-2,2,6,6-tetramethylpiperidine ring, were studied by $\mathrm{X}$-band EPR spectroscopy and their properties were compared with two other biradicals $\mathrm{S}\left[\left(\mathrm{CH}_{2}\right)_{4} \mathrm{COOR}_{6}\right]_{2}(\mathrm{B3})$ and $\left(\mathrm{CH}_{2}\right)_{5}\left[\mathrm{CONHR}_{6}\right]_{2}(\mathrm{~B} 4)$ investigated earlier. All EPR spectra are described well in terms of the three-conformational model. The energetic parameter, $\varepsilon$, describing the temperature dependence of the spin-exchange strongly depends on the solvent macroscopic parameters, characterizing bulk properties of the solvent, i.e., between EPR parameter $\varepsilon$ and the solvent viscosity energy, $E_{\eta}$. The macroscopic influence was found from linear trends in plots concerning viscosity, with some degree of deviance found in the case of two solvents cyclohexanol and 1-octanol. Possibly, this may, at least partially, be explained by the fact that $E_{\eta}$ has been determined in the literature using a comparatively narrow range of temperatures fit to a simple exponential model.

Acknowledgements A.I.K. and P.V.P. are thankful to Mr. O. A. Romanov for technical assistance during manuscript preparation.

Author Contributions GG: supervision, validation, editing, writing—reviewing. VAT: visualization, data curation, investigation. PVP: investigation, software, methodology. AIK: conceptualization, writingoriginal draft preparation. All authors approved the final version of the manuscript. 
Funding Open access funding provided by Graz University of Technology. V. A. T. would like thank the Austrian Exchange Service for an Asea-Uninet-Scholarship. G. G. thanks the Asea-Uninet Network for financial support.

Data Availability All data needed to evaluate the conclusions in the paper are present in the paper.

\section{Compliance with Ethical Standards}

Conflict of interest The authors declare no competing interests.

Open Access This article is licensed under a Creative Commons Attribution 4.0 International License, which permits use, sharing, adaptation, distribution and reproduction in any medium or format, as long as you give appropriate credit to the original author(s) and the source, provide a link to the Creative Commons licence, and indicate if changes were made. The images or other third party material in this article are included in the article's Creative Commons licence, unless indicated otherwise in a credit line to the material. If material is not included in the article's Creative Commons licence and your intended use is not permitted by statutory regulation or exceeds the permitted use, you will need to obtain permission directly from the copyright holder. To view a copy of this licence, visit http://creativecommons.org/licen ses/by/4.0/.

\section{References}

1. A.L. Buchachenko, V.A. Golubev, A.A. Mejidov, E.G. Rozantsev, Theoret. Exp. Khim. 1, 249 (1965)

2. E.G. Rozantsev, V.I. Suskina, Izv. AN SSSR. Ser. Khim 9, 2148 (1968)

3. E.G. Rozantsev, Free Nitroxyl Radicals (Plenum Press, New York, 1970)

4. V.N. Parmon, A.I. Kokorin, G.M. Zhidomirov, K.I. Zamaraev, Mol. Phys. 30, 695 (1975)

5. V.N. Parmon, A.I. Kokorin, G.M. Zhidomirov, Russ. J. Struct. Chem. 18, 104 (1977)

6. S.V. Kozlov, A.I. Kokorin, A.B. Shapiro, E.G. Rozantsev, Vysokomolek. Soed. 23, 323 (1981)

7. S.A. Dikanov, G.I. Shchukin, I.A. Grigoŕev, S.I. Rukin, L.B. Volodarsky, Izv. AN SSSR. Ser. Khim. 3, 565 (1985)

8. I.A. Grigor'ev, S.A. Dikanov, Synthesis, properties, applications, in Imidazoline nitroxides, 1st edn., ed. by L.B. Volodarsky (CRC Press, Boca Raton, 1988), pp. 77-150

9. S. Sankarapandi, J.M. Rifkind, P.T. Manoharan, Proc. Indian Acad. Sci. Chem. Sci. 106, 1329 (1994)

10. S. Sankarapandi, M. Sukumar, P. Balaram, P.T. Manoharan, Biochem. Biophys. Res. Commun. 213, 439 (1995)

11. V.A. Tran, K. Rasmussen, G. Grampp, A.I. Kokorin, Appl. Magn. Reson. 32, 395 (2007)

12. G. Ionita, V. Meltzer, E. Pincu, V. Chechik, Org. Biomol. Chem. 5, 1910 (2007)

13. J. Szydłowska, K. Pietrasik, Ł. Głaz, A. Kaim, Chem. Phys. Lett. 460, 245 (2008)

14. A. Kaim, K. Pietrasik, T. Stokłosa, Eur. Polym. J. 46, 519 (2010)

15. A. Kaim, J. Szydłowska, K. Pietrasik, Macromol. Res. 19, 1041 (2011)

16. E.G. Ionita, G.A. Vorobieva, V. Chechik, A.I. Kokorin, Appl. Magn. Reson. 46, 251 (2015)

17. B. Mladenova-Kattnig, G. Grampp, A.I. Kokorin, Appl. Magn. Reson. 46, 1359 (2015)

18. S.S. Eaton, L.B. Woodcock, G.R. Eaton, Concepts Magn. Reson. A 47A, e21426 (2019)

19. A.I. Kokorin, Ionic Liquids, Theory and Applications (InTech Publ., Rijeka, 2011), pp. 183-200

20. D. Wang, Y. Ma, B. Wolf, A.I. Kokorin, M. Baumgarten, J. Phys. Chem. A 122, 574 (2018)

21. A.I. Kokorin, E.N. Golubeva, V.A. Tran, B. Mladenova, T. Kálai, K. Hideg, G. Grampp, Appl. Magn. Reson. 44, 1041 (2013)

22. O.I. Gromov, E.N. Golubeva, V.N. Khrustalev, T. Kálai, K. Hideg, A.I. Kokorin, Appl. Magn. Reson. 45, 981 (2014)

23. A.I. Kokorin, O.I. Gromov, T. Kálai, K. Hideg, Appl. Magn. Reson. 47(11), 1283-1293 (2016) 
24. A.I. Kokorin, O.I. Gromov, P.V. Dorovatovskii, V.A. Lazarenko, V.N. Khrustalev, K. Hideg, T. Kálai, Appl. Magn. Reson. 50, 425 (2019)

25. C. Reichard, Chem. Rev. 94, 2319 (1994)

26. Y. Marcus, The Properties of Solvents (Wiley, Chichester, 1998)

27. G. Grampp, K. Rasmussen, Phys. Chem. Chem. Phys. 4, 5546 (2002)

28. A.B. Shapiro, V.I. Suskina, V.V. Fedorova, E.G. Rozantsev, Izv. AN SSSR. Ser. Khim. 4, 694 (1970)

29. J.A. Riddick, W.B. Bunger, K.T. Sakano, Organic Solvents, Physical Chemistry and Methods of Purification, in Techniques of chemistry, 2nd edn., ed. by K.T. Sakano (Wiley, New York, 1986)

30. Yu.N. Molin, K.M. Salikhov, K.I. Zamaraev, Spin Exchange (Springer, Berlin, 1980)

31. A.I. Kokorin, Appl. Magn. Reson. 26, 253 (2004)

32. R. Gilmont, Meas Control 10, 36 (2002)

33. M.K. Karapetýants, K.-S. Yen, Izv. Vysshikh Uchebn. Zavedenii Khim. i Khim. Tekhnol. 4, 580 (1961)

34. J. Barthel, R. Buchner, M. Münsterer, Chemistry Data Series. Part 2a: Electrolyte Data Collection, 12th edn. (Dechema, Germany, 1996)

35. S.P. Patil, A.S. Chaudhari, M.P. Lokhande, M.K. Lande, A.G. Shankarwar, S.N. Helambe, B.R. Arbad, S.C. Mehrotra, J. Chem. Eng. Data 44, 875-878 (1999)

36. S.K. Garg, C.P. Smyth, J. Chem. Phys. 46, 373-378 (1967)

37. M.L.T. Asaki, A. Redondo, T.A. Zawodzinski, J. Chem. Phys. 116, 10377-10385 (2002)

38. G. Grampp, K. Rasmussen, A.I. Kokorin, Appl. Magn. Reson. 26, 245 (2004)

Publisher's Note Springer Nature remains neutral with regard to jurisdictional claims in published maps and institutional affiliations. 